\title{
Espaço e desamparo em A obscena Senhora D - uma reflexão interdisciplinar por meio da arquitetura e da psicanálise a partir da novela de Hilda Hilst
}

\begin{abstract}
Humberto Lima
"Os poetas e os romancistas são aliados preciosos, e o seu testemunho merece a mais alta consideração, porque eles conhecem, entre o céu e a terra, muitas coisas que a nossa sabedoria escolar nem sequer sonha ainda. São, no conhecimento da alma, nossos mestres, que somos homens vulgares, pois bebem de fontes que não se tornaram ainda acessíveis à ciência."
\end{abstract} Sigmund Freud. As palavras de Freud (1999).

\begin{abstract}
Resumo: Este texto consiste numa interpretação intersemiótica. Justapondo teorias que versam sobre o espaço arquitetônico e a psicanálise, o ensaio aborda questões subjetivas da arquitetura, a partir da novela $A$ obscena Senhora $D$, de Hilda Hilst (2001). Partindo do pressuposto que a arquitetura se faz para além da sua materialidade, discute-se a conexão do humano com o espaço construído, explorando o conceito do Desamparo freudiano como possível elemento estruturante de tal relação. Teoria e ficção, espaço literário e arquitetônico, personagens e sujeito humano se fundem na tentativa de explorar e explicar os processos inconscientes e de ordem simbólica que a permeiam.
\end{abstract}

Palavras-chave: Espaço arquitetônico. Desamparo. Psicanálise. Espaço literário.

\begin{abstract}
This text consists of an intersemiotic interpretation. By juxtaposing theories on architectural space and psychoanalysis, the essay approaches subjective questions of architecture, through Hilda Hilst's novel A obscena Senhora D (2001). Based on the assumption that architecture is done beyond its materiality, the relationship between the human and the constructed space is discussed, exploring the concept of Freudian Helplessness as a possible structuring element of such a relation. Theory and fiction, literary and architectural space, characters and human being, are merged in the attempt to explore and explain the unconscious and symbolic processes that permeate it.
\end{abstract}

Keywords: Architectural space. Helplessness. Psychoanalysis. Literary space.

Resumé: Ce texte est une interprétation intersémiotique. En juxtaposant des théories sur l'espace architectural et la psychanalyse, l'essai aborde des questions subjectives d'architecture, tirées du roman A obscena Senhora $D$, de Hilda Hilst (2001). Basé sur I'hypothèse que l'architecture est faite au-delà de sa matérialité, la connexion entre l'être

\footnotetext{
${ }^{1}$ Mestrando no Programa de Pós-Graduação em Desenvolvimento Urbano (MDU) na Universidade Federal de Pernambuco.
} 
humain et l'espace construit est discutée, en explorant le concept du Détresse freudien comme un élément possible pour structurer cette relation. La théorie et la fiction, l'espace littéraire et l'architectural, les personnages et le sujet humain se fondent dans la tentative d'explorer et d'expliquer les processus inconscients et symboliques qui la traversent.

Mots-clès: Espace architectural. Détresse. Psychanalyse. Espace littéraire.

Tal qual o espaço da Arquitetura, o espaço da Literatura se faz em um vazio pleno de significados. Como no do mundo real, este se enche de sentido quando personagens o habitam; ou nele "andam e vivem" (ZEVI, 1997, p. 18). Em contrapartida, a própria arquitetura seria um discurso narrativo, pois as palavras que se falam e se escrevem a fim de descrevê-la direcionam a formas de pensar e viver o espaço arquitetônico (FORTY, 2004). Ou, como preferem Markus e Cameron (2002), textos precedem, acompanham e transformam espaços.

A palavra escrita é veículo que carrega e demanda as vivências de quem escreve e de quem lê. $\mathrm{O}$ espaço por ela definido se constrói simbolicamente e, ainda que não se materialize, constitui realidades e sentidos personalizados; ou imagens variacionais, como conceitua Bachelard (2008). O semiólogo Umberto Eco (1986) afirma que apenas aparentemente os objetos arquitetônicos estão presos a uma simples denotação primária, pois, na verdade, possuem uma série de significados secundários conotativos. Desse modo, cada pessoa, à sua maneira, poderia extrair dessa linguagem o conhecimento próprio de um universo de símbolos e representações.

Para a Psicanálise - criação estruturada na medicina e numa "verdade peculiar à literatura, que é em geral mais apropriada para a compreensão do homem que a própria ciência regular" (HERRMANN, 1999, p. 18) - tal premissa também é válida para os sonhos. Ao estabelecer uma relação entre o sonho onírico e a arte literária, Kaufmann (1996, p. 156) assegura: sonho é "escrita figurada". Sonhar é uma maneira de exprimir palavras e frases por meio de figuras e sinais. Escrever é o caminho inverso. A justaposição entre esses "tipos de sonhos" se daria pelas similitudes de suas metáforas, ou pelos usos dos mesmos "processos estilísticos", como observa Certeau (1998, p. 183). Embora seja um, um sonho sonhado enquanto se dorme, e outro, um sonho tecido em palavras; são ambos, passíveis de interpretação. 
Interpretar um sonho, aliás, significa indicar seu sentido e demanda uma atitude de criação poética (FREUD, 2013). E o "sonho escrito" que conduz este ensaio e possibilita uma análise à luz de conceitos da Arquitetura e da Psicanálise é $A$ obscena Senhora $D$ - uma novela da poeta, ficcionista e dramaturga contemporânea brasileira, Hilda Hilst (1930-2004), escrita em 1981. O livro conta a trajetória de uma mulher em estado de luto - Hillé - devido à morte do companheiro - Ehud. Inquieta, ela se retira da cena cotidiana (por isso, também obscena) e passa a viver no vão da escada da sua casa.

Compreendendo Arquitetura, Psicanálise e Literatura como veículos de expressão e constituição de novas subjetividades, nesse texto em prosa de Hilst, escritora declaradamente interessada pelos estudos da psicanálise e que tinha 0 "pai", Sigmund Freud, como referência intelectual, viu-se a oportunidade de realizar um ensaio acadêmico, valendo-se da intersemiose para reunir conceitos e ideias de distintas áreas. $O$ ensejo é não o de confrontar tais disciplinas já constituídas, mas vislumbrar algum objeto novo, que, porventura, não as pertença, como pensa Barthes (1988) ao discutir a interdisciplinaridade. Guiado pela prosa de Hilda Hilst, aqui o exercício se dá no sentido de, especificamente, refletir acerca do conceito do Desamparo freudiano e especular seus possíveis rebatimentos na relação do humano com o espaço da arquitetura.

Freud explica: para experimentar o desamparo, basta nascer. Em um recém-nascido, este é um estado inicial, marcado pela dependência total e involuntária do infante para suprir suas necessidades básicas e outras tensões. "O organismo humano é, a princípio, incapaz de promover essa ação específica. Ela se efetua por ajuda alheia" (FREUD, 1969, p. 431). Eis o Desamparo original - registro da necessidade do outro por uma questão de sobrevivência.

Crescidos, os indivíduos ainda terão que admitir toda a extensão do seu desamparo perante as incertezas de se estar no mundo, pois "não podem mais ser o centro da criação, o objeto de eterno cuidado por parte de uma Providência beneficente" (Freud, 1969, p. 63). Portanto, vivem, essencialmente, desamparados.

O conceito do Desamparo freudiano pode ser compreendido nas entrelinhas de uma angústia permanente; em uma busca constante e inconsciente por uma falta igual. É dependência biológica, mas também dependência de amor e desejo (ROCHA, 1999). É elemento estruturante da 
subjetividade e parte da condição humana. "E por condição humana, entendo o nosso modo de ser situado no espaço e limitado pelo tempo, nosso modo de ser no incessante irreversível fluir da existência" (ROCHA, 2016, p. 143).

Hillé, A obscena Senhora $D$, é a personificação desse estado de Desamparo. Quem a conhece, sabe. E ela se apresenta agora, na particular escrita hilstiana.

\begin{abstract}
Vi-me afastada do centro de alguma coisa que não sei dar nome nem porisso irei à sacristia, teófaga incestuosa, isso não, eu Hillé também chamada por Ehud A Senhora D, eu Nada, eu Nome de Ninguém, eu à procura da luz numa cegueira silenciosa, sessenta anos à procura do sentido das coisas. Derrelição Ehud dizia, Derrelição - pela última vez Hillé, Derrelição quer dizer desamparo, abandono, e porque me perguntas a cada dia e não reténs, daqui por diante te chamo $\mathrm{A}$ Senhora D. D de Derrelição, ouviu? Desamparo (p. 17)
\end{abstract}

Desamparados, marcados pela incompletude, seres humanos desejantes, a exemplo de Hillé, instintivamente tendem a buscar o que Ihes faltam. E buscam por amparo. Por vezes, logram encontrá-lo no espaço da arquitetura. Plausível, pois, como afirma Norberg-Schulz, um dos propósitos da arquitetura é fornecer um ponto de apoio existencial (NORBERG-SHULZ, apud. NESBITT, 2008). E por que não dizer fornecer amparo?

Arquitetonicamente, o símbolo maior do abrigo/amparo é a casa. Hipoteticamente, o primeiro abrigo arquitetado pelo humano foi "a casa de Adão no paraíso". O dono, Adão, teria a construído para proteger-se da chuva, quando expulso do éden. É o que confabula Rykwert (2003) ao teorizar acerca da cabana primitiva - esta que teria sido a origem de toda a arquitetura. Mas, esse propósito puramente material e funcionalista não contempla toda a simbologia que uma casa representa, "porque a casa é o nosso canto no mundo. Ela é, como se diz amiúde, o nosso primeiro universo. É um verdadeiro cosmos." (BACHELLARD, 2008, p. 24). Ela ultrapassa os limites do abrigo físico; conforma abrigo subjetivo de dimensão onírica. Ora, para todo ser não existe uma casa dos sonhos?

E como seria a casa dos sonhos da Senhora D? Por que teria ela se recolhido embaixo da escada? Por que abriu mão de algumas liberdades? Sua casa Ihe sobrava? Ou não Ihe era bastante? Decerto, algo devia Ihe faltar.

\footnotetext{
${ }^{2}$ Todas as citações destacadas dos parágrafos, a exemplo desta, foram extraídas do livro $A$ obscena Senhora D (HILST, 2001). Portanto, nestes casos, optou-se por mencionar apenas as páginas correspondentes à citação na referida obra.
} 
desde sempre a alma em vaziez, buscava nomes, tateava cantos, vincos, acariciava dobras, quem sabe se nos frisos, nos fios, nas torçuras, no fundo das calças, nos nós, nos visíveis cotidianos, no ínfimo absurdo, nos mínimos, um dia a luz, o entender de nós todos o destino, um dia vou compreender, Ehud compreender o que?

isso de vida e morte, esses porquês (p. 17)

De "alma vazia", A Senhora D busca respostas. Guiada por suas pulsões, tateia cantos.

Para Bachelard (2008, p. 145) "todo canto de uma casa, todo espaço reduzido onde gostamos de nos encolher, nos recolher em nós mesmos, é, para a imaginação, uma solidão". E em que consiste a solidão se não no mal estar da falta? Teria sido este o impulso que direcionou Hillé a refugiar-se no vão da escada? Teria sido esta uma tentativa dela separar-se do todo e minimizar, de alguma forma, sua aflição por se encontrar desamparada no mundo?

Quem a mim me nomeia o mundo? Estar aqui no existir da Terra, nascer, decifrar-se, aprender a deles adequada linguagem, estar bem não estou bem, Ehud ninguém está bem, estamos todos morrendo ( $p$. 24).

É de completo desamparo a experiência humana de incapacidade e impotência diante da marcha do tempo. Nessa inexorável marcha, a única certeza é a morte (ROCHA, 1999). Em palavras, Hillé expõe essa condição. Em ação, supõe-se que tenha sido levada a amenizá-la na espacialidade de um canto da casa.

Freud (2010, p. 18) diz que "a casa para moradia constituiu um substituto do útero materno, o primeiro alojamento, pelo qual, com toda probabilidade, o homem ainda anseia, e no qual se achava seguro e se sentia à vontade". A casa seria, portanto, mais uma dessas coisas que o ser humano fez surgir na Terra, "como se fosse um recém-nascido desamparado" (FREUD, 2010, p. 18). Uma edificação com propriedades maternais, um arquétipo concebido para realizar desejos, através de um processo substitutivo e inconsciente.

$D$, primeira letra de Derrelição, doce curva comprimindo uma haste, verticalidade sempre reprimida (p. 29) 
D de Desamparo, mas também, D de Desejo ${ }^{3}$. Freudiano, Inconsciente, desnaturalizado e lançado na ordem do simbólico, como adjetiva Garcia-Roza (1992). Desejo de retornar à completude da experiência espacial uterina; ao "paraíso" idealizado pelo psiquismo; ao estado oposto ao do Desamparo. A recolhida de Hillé é marca simbólica desse desejo inscrita na realidade do espaço. Em sua ânsia por amparo, a Senhora Desamparada estabelece um elo com a escada-útero da sua casa-mãe.

Lixo as unhas no escuro, escuto, estou encostada à parede no vão da escada, escuto-me a mim mesma, há uns vivos lá dentro além da palavra, expressam-se mas não compreendo, pulsam, respiram, há um código no centro, um grande umbigo, dilata-se, tenta falar comigo, espio-me curvada (p. 21-22).

Escuro, parede, dentro, centro; umbigo! Palavras que definem um espaço. Mas do útero ou da escada? De ambos? Curvada, como que um feto em sua plenitude, A Senhora $D$ parece buscar pela experiência espacial primeira e de inteira satisfação: habitar o útero.

Mas habita-se o útero?

desconheces quase toda tua totalidade, que contornos havia aos quinze anos aos vinte, lá dentro do ventre, que águas, plasma e sangue, que rio te contornava? que geografia se desenhava no teu rosto, e o rosto daquela que te carregava na barriga, como era? como te carregava essa que habitavas? (p. 65)

Águas, plasma e sangue. Rio. Um ventre biológico e geográfico. Cavidade e espaço em sentidos múltiplos. Habitável. A primeira experiência espacial da obscena Senhora D (e de todo ser). A primeira moradia humana. Lugar do amparo?

No curso do que aqui se ensaia, especula-se uma relação lógica: se vir a estar "fora do útero", para a psicanálise, determina a condição de Desamparo; vir a estar "dentro do útero" determinaria a condição de Amparo. Especula-se mais: "estar dentro"; "encontrar-se contido" é um desejo. No intuito de realizá-lo, arquiteta-se para habitar um espaço interior. Afinal, "a essência do construir é

\footnotetext{
${ }^{3}$ Atenta-se que esta construção frasal se faz possível em língua portuguesa, mas não nos originais escritos freudianos, em língua alemã. Na língua mãe do psicanalista, grafa-se, respectivamente, Hilflosigkeit e Traumdeutung para referir-se ao Desamparo e ao Desejo aqui abordados.
} 
deixar habitar". Habitar é um "traço essencial do ser" (HEIDEGGER, 1954, s/p.). Habitar é, também, amparar-se.

À arquitetura é delegada a função de assegurar esse valor humano. Ela, como expressão perfeita de atributos do útero materno, segundo Coelho Netto (1984), teria decidido por privilegiar o espaço interior - sua preocupação primeira e fundamental. Por isso, através dos séculos, obedeceu à "orientação de manipular por excelência um Espaço Interior concebido como oposição ao Exterior e com o que se procurava uma proteção necessária" (COELHO NETO, 1984, p. 30). Proteção para além do real. Até mesmo ilusória. Simbólica.

Entende-se, pois, que fazer arquitetura é necessidade e desejo. Ou, em outras palavras, fazer arquitetura é atender a demandas físicas e psíquicas. É Consciência e Inconsciência; Concretude e Imaterialidade. E parece ser ainda mais que isso.

É Michel de Certeau (2009) quem diz que os habitats sucessivos nunca desaparecem; eles vivem invisíveis e presentes nas memórias e nos sonhos de cada pessoa. E esses habitats parecem ser contados a partir do útero. Olivier Marc (1972) afirma que os construtores da cabana primitiva teriam sido levados a construí-la por perseguirem um modelo anterior ao nascimento: o interior do ventre materno, o qual se desenha no psiquismo como uma casa matriz. Arquitetar, ou construir, assumiria, assim, o feitio de pulsão criativa, de resposta a demandas psíquicas, anseio de atender a determinada forma de morar, habitar, experimentar espaços; constitui especificidade do gênero humano, como diz Françoise Choay (2006). O ato de construir é um poder inerente à espécie. É competência genérica, à semelhança do advento da fala. É uma maneira de afirmar fidelidade ao espaço através de um processo criativo imprevisível. Nada mais é que uma consequência (CHOAY, 2006). Impulso natural e humano, já que o corpo reclama espacialidade; deseja ser envolvido espacialmente. Seria isto sintoma de Desamparo?

suportaria guardar no peito esse reservatório de desejos [...] ? (p. 33).

A arquitetura se faz para proteger, mas "não apenas das hostilidades ambientais, sua face mais visível, mas também em sua dimensão simbólica do desamparo que marca o humano frente à experiência de existir" (LEITÃO, 2007, p. 56). Pois, à arquitetura cabe a função de conceber um espaço-mãe capaz de 
acolher esse vazio do Eu com o vazio próprio da sua matéria: o Espaço - objeto de realização de desejos; o Interior - lugar de memória e cavidade desde muito cedo apreendida; onde bem se deseja estar.

Este espaço interior é o "protagonista da arquitetura" (ZEVI, 1997, p. 17). Ele é a reconstrução imagética da unidade particular onde o ser se sentia tão bem acolhido, diria Olivier Marc (1972). É o invólucro do humano privado; estrutura que sustenta suas ilusões. Tão significativo que é ali que os habitantes imprimem suas marcas. É ali que se apresentam os objetos de uso mais cotidianos, mas também "um mundo em que as coisas estão liberadas de ser úteis" (BENJAMIN, 2009, p. 45).

Deito sobre a palha do meu vão de escada, toco dentro das águas os peixes pardos, esfarelam-se, é preciso recortar novos, talvez deva usar um papel mais encorpado para resistirem mais tempo dentro d'água ( $p$. 33).

"Habitar significa deixar rastros", diz Benjamin (2009, p. 46). E no interior do seu simulacro uterino, A Senhora $D$ vai deixando os seus. Ela afronta a racionalidade espacial, contraria a funcionalidade da casa, mora em um "buraco", mas no seu vão de escada, deixa rastros, visto que lá habita. Palha sobre o chão é leito. Peixe de papel dentro d'água é representação de coisa viva. Elementos que dizem sobre a dimensão objetiva e a marca subjetiva, presentes tanto na construção do sujeito, quanto na produção do espaço arquitetônico. Simbolizam uma profusão de "coisas inventadas", seja na materialidade ou na imaterialidade, para atender aos desejos de um ser humano existencialmente desamparado. Representam um ponto de contato entre o conceito de Espaço, para a arquitetura, e o de Desejo, para a psicanálise; contemplados pela noção de Vazio (espacial), de Falta (psíquica).

Retomando o fio narrativo da história contada por Hilst (2001), pode-se dizer que a morte de Ehud, na vida de Hillé, representa o ápice do seu estado de desamparo. Perder o companheiro acentuou sua excentricidade, no sentido de que, cada vez mais, ela foi sendo afastada do centro de algo que não sabia dar nome; foi sendo deslocada. E, acometida por um crônico "mal estar moderno", chegou ao ponto de renegar completamente o espaço externo; enclausurou-se; trancou-se. Passou a viver para dentro. Do espaço e de si mesma. Narcísica, obscena e desamparada que é, retirou-se. 
por que fecha sempre as janelas?

e por que devo abri-las?

e por que as abre de repente e assusta as gentes e grita?

o corpo é quem grita esses vazios tristes (p. 32).

Será que se Freud analisasse a personagem da Senhora D, concluiria que tamanho era o seu desamparo que ela procurou escapar por uma trajetória de regressão, tendo "um retorno da libido a anteriores pontos de interrupção de seu desenvolvimento"? (FREUD, 1996 p. 346). Afinal, Hillé não dá conta da sua adultez desamparada. Como mecanismo de defesa, talvez regresse na tentativa de encontrar alguma satisfação, ao eximir-se da responsabilidade de existir, ou ao menos diminuí-la. Por isso, assume um comportamento infantil, torna-se inconsequente e impulsiva, prega peças na vizinhança, assusta as gentes. É puro instinto. Animaliza-se.

Casa da Porca, assim chamam agora a minha casa (p. 20)

Abro a janela enquanto ele se afasta, invento rouquidões, grunhidos, coxos, uso a máscara de focinhez e espinhos amarelos [...] (p. 32).

Por vezes, a Senhora parece criança, apesar da maturidade e da profundidade dos seus pensamentos. Cuidada por Ehud, age como típica criatura desamparada. Reclama a satisfação de seus desejos através de gritos e outros impulsos, mas não preenche o vazio do corpo nem o da alma. Em sessenta anos de busca, numa cegueira silenciosa, sinestesicamente foi parar embaixo da escada.

loucura é o nome da tua busca. esfacelamento.

cisão.

derrelição (p. 56).

Desamparo.

Falta.

Incompletude que a levou a improvisar refúgio naquele vão que deveria Ihe prover algum conforto - sobretudo psíquico - e, ao menos, aliviar seu latente estado de desamparo. Simbólico casulo de Hillé.

Senhora $D$, é definitivo isso de morar no vão da escada? você está me ouvindo Hillé? olhe, não quero te aborrecer, mas a resposta não está aí, ouviu? nem no vão da escada, nem no primeiro degrau aqui de cima [...] (p. 18) 
Não é definitivo, certamente. Ela sabe.

Agora que Ehud morreu vai ser mais difícil viver no vão da escada ( $p$. 18).

Nomeada ao mundo, a contragosto, mais uma vez Hillé perde sua "providência beneficente", como definiu Freud (1969). Dada as circunstâncias, será forçada a deixar o interior da escada-útero. Deverá arriscar-se no mundo, lá fora. Simbolicamente, nascerá de novo. E nascimento é expulsão, separação de unidade, imposição que se dá apesar dos desejos da mãe e do filho (MARC, 1972). Condição de extrema derrelição.

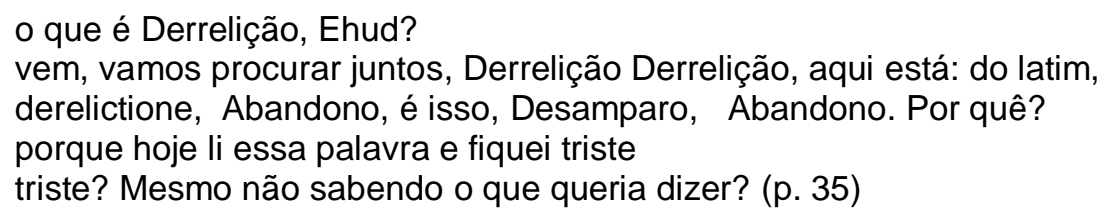

Força motriz inconsciente. Lacuna que deslocou A Senhora D existencialmente e espacialmente. Falta que inquieta e põe o ser em movimento. Vazio que implica em transitividade, em não permanência; que faz caminhar. Assegura Certeau (1998, p. 183): "caminhar é ter falta de lugar. É o processo indefinido de estar ausente e à procura de um próprio".

Por quais caminhos esta falta guiará Hillé? A que lugares a levará? A Senhora $D$ encontrará um novo canto? Encontrará a si mesma?

A literatura não diz. Mas as ideias aqui discutidas sugerem que a desamparada senhora continuará reclamando espaço; abrigo para o corpo e para a alma em luto. Hillé não cessará sua busca por amparo. Movida pela incompletude que a define, seu desejo de conquistar um canto no mundo não findará. Diria Zeferino Rocha (2016, p. 145): "se o desamparo era a sua miséria, a responsabilidade de ser livre e poder dar um sentido à sua vida é a sua grandeza".

você vai achar, Hillé, seja o que for que você procura.

como você sabe?

porque nada nem ninguém aguenta ser assim perseguido (p. 35). 
Seja como for, Hillé seguirá seu percurso, pois, Desamparada, A obscena Senhora D deseja. Sempre inserida em uma cena espacial, supõe-se que sua profunda "vaziez" garantirá a perseguição por acolhimento físico e psíquico no espaço da arquitetura, na instância da literatura - a exemplo de todo ser humano, no espaço da arquitetura do mundo real.

Desamparo, Abandono, assim é que nos deixaste (p. 36).

\section{Referências}

BACHELARD, Gaston. A poética do espaço. São Paulo: M. Fontes, 1989.

BARTHES, Roland. Aula. Trad. Leyla Perrone-Moisés. São Paulo: Cultrix, 1988. BENJAMIN, Walter. Passagens. Belo Horizonte: UFMG, 2009.

CERTEAU, Michel. A invenção do cotidiano: artes de fazer. Petrópolis: Vozes, 1998.

A invenção do cotidiano: morar, cozinhar. Petrópolis: Vozes, 2009.

CHOAY, Françoise. Le De re aedificatoria et l'instituition de la societé. In:

Pour une anthropologie de l'espace. Paris: Éditions du Seuil, p. 374-401, 2006.

COELHO NETTO, José Teixeira. A construção do sentido na arquitetura. São Paulo: Perspectiva, 1984.

ECO, Umberto. Function and sign: semiotics of architecture. In: GOTTDIENER, M; FORTY, Adrian. Words and buildings: a vocabulary of modern architecture. London: Thames \& Hudson, 2004.

FREUD, Sigmund. (1916). Conferência XXIl: algumas ideias sobre desenvolvimento e regressão - etiologia. In: S. Freud, Edição Standard brasileira das obras psicológicas completas de Sigmund Freud (Vol. 16). Rio de Janeiro: Imago, 1996.

. (1895). Projeto para uma psicologia científica. Rio de Janeiro: Imago, 1969.

(1916). Alguns tipos de caráter encontrados no trabalho psicanalítico. In: . Obras completas. Rio de Janeiro: Imago, 1976.

. (1927). O Futuro de uma ilusão. Rio de Janeiro: Imago, 1969. 
(1930-1936): O mal-estar na civilização e outros textos. São Paulo: Companhia das Letras, 2010.

. O método de interpretação dos sonhos. Porto Alegre: L\&PM, 2013.

GARCIA-ROZA, Luiz Alfredo. O desejo. In:___. Freud e o inconsciente. Rio de Janeiro: Jorge Zahar, p. 139-150, 1992.

HEIDEGGER, Martin. Construir, habitar e pensar. Bauen, Wohnen, Denken. 1951. Conferência pronunciada por ocasião da "Segunda Reunião de Darmstadt", publicada em Vortage und Aufsatze, G. Neske, Pfullingen, 1954. Disponível em: $<<w w w . p r o u r b . f a u . u f r j . b r / j k o s / p 2 /$ heidegger_construir,\%20habitar,\%20pensar.pdf >>. Acessado em: 26 nov. 2017.

HERRMANN, Fábio. A psique e o eu. São Paulo: Hepyché, 1999.

HILST, Hilda. A obscena senhora D. São Paulo: Globo, 2001.

KAUFMANN, Pierre. Dicionário enciclopédico de psicanálise: o legado de Freud e Lacan. Rio de Janeiro: Jorge Zahar, 1996.

LEITÃO, Lúcia. Entra na tua casa: anotações sobre arquitetura, espaço e subjetividade. In: AMORIM, Luiz; LEITÃO, Lúcia (orgs.). A casa nossa de cada dia. Recife: Ed. Universitária UFPE, p. 47-70, 2007.

MARC, Olivier. La psychanalyse de la maison. Paris: Éditions du Seuil, 1972.

MARKUS, Thomas A.; CAMERON, Deborah. The words between the spaces: buildings and language. London and New York: Routledge, 2002.

NESBITT, Kate (org.). Uma nova agenda para a arquitetura: antologia teoria (1965-1995). 2.ed. rev. São Paulo: Cosac Naify, 2008.

ROCHA, Zeferino. Desamparo e metapsicologia: para situar o conceito de Desamparo no contexto da metapsicologia freudiana. In: SíNTESE REVISTA DE FILOSOFIA. Síntese: Belo Horizonte, v.26, n.86, pp. 331- 346, 1999.

Freud e o Desamparo (Hilflosigkeit). In: . Ensaios psicanalíticos com interface com a Filosofia. Recife: CEPE, p.133-148, 2016.

RYKWERT, Joseph. A casa de Adão no paraíso. São Paulo: Perspectiva, 2003. SOUZA, Paulo César de. As palavras de Freud. São Paulo: Companhia das Letras, 1999.

ZEVI, Bruno. Saber ver a arquitetura. São Paulo: M. Fontes, 1997.

Recebido em 19/07/2018.

Aprovado em 28/08/2018. 